\title{
Cuando María Cinta Balagué radió el primer magazine
}

\author{
Sílvia EsPinOSA MirabeT \\ Universitat de Girona \\ Silvia.espinosam@udg.edu
}

\begin{abstract}
Resumen
Este artículo revelará quién fue la primera locutora de radio en Cataluña y cuáles fueron sus aportaciones al medio. Maria Cinta Balagué, culta y conservadora, desarrolló el primer programa de radio con formato de magazine en un contexto radiofónico de monólogos y conferencias protagonizados por voces masculinas. Ocurrió en Radio Barcelona en la franja programática dedicada a las mujeres durante la década de los años 20.
\end{abstract}

Palabras Clave:_Radio; locutora; magazine; historia.

\section{When Maria Cinta Balagué broadcasted the first radio magazine}

\begin{abstract}
This paper will reveal who was the first radio broadcaster of Catalonia and what were her contributions to the medium. Maria Cinta Balagué, a cultured and conservative woman, developed the first radio magazine when in the early 20 s all were monologues and lectures in a catalan radio stations. It happened in Barcelona in a feminine program.
\end{abstract}

Key words: Radio; speaker; magazine; history.

Referencia normalizada:

Espinosa Mirabet, S. (2013) Cuando María Cinta Balagué radió el primer magazine. Historia y Comunicación Social. Vol. 18 Nºspecial Octubre. Págs. 157-167

\section{Sumario}

1. Introducción. 2. Metodología. 3. Las emisiones para mujeres en la radio catalana de los años 20. 3.1.¿Por qué se contrataron locutoras? 3.2. Los primeros programas femeninos en Cataluña. 3.2.1. La primera locutora de radio en Cataluña. 4. Conclusiones. 5. Referencias bibliográficas. 6. Notas

\section{Introducción}

La historia de la radio en España ha atribuido erróneamente, el título de primera locutora de Radio Barcelona a María Sabaté cuando en realidad, tal com apuntó Balsebre (2001) y probó la tesis doctoral Les locutores de ràdio a Catalunya, 19241939 (Espinosa, 2008) dirigida por él, Sabaté nunca fue locutora de radio ${ }^{1}$. Era secretaria de dirección y trabajó con los pioneros de Radio Barcelona ejerciendo como tal gracias a la esmeradísima formación que había recibido en el prestigioso Instituto de 
Cultura y Biblioteca Popular de la Mujer en Barcelona. Como se evidenciará en este artículo, la primera locutora que así actuó fue María Cinta Balagué, trabajadora del Ayuntamiento de Barcelona que acabó creando el primer programa magazine dedicado al público femenino.

En los años 20 del siglo pasado la programación radiofónica era muy escasa y muy del agrado de un reducido, pero selecto, grupo de oyentes: el público acaudalado que podía pagar el impuesto por tenencia de aparato receptor y además comprárselo. Radio Barcelona retransmitía conciertos de música clásica, ofrecía conferencias sobre temas vinculados a la técnica (incluso la radiofónica) y se ocupaba de la bolsa, por poner sólo algunos ejemplos. Las voces protagonistas de esa reducida programación eran masculinas. El locutor emblemático era Rafael del Caño, que ya actuó de presentador en la sesión inaugural de la radio y las mujeres radioescuchas debían contentarse con las peroratas de Joaquín Arrarás en sus Charlas femeninas.

Este panorama cambió radicalmente cuando María Cinta Balagué creó un formato de programa coral, repleto de contenidos diferentes que ponían en antena femeniles voces dirigidas siempre por ella. Ese primer espacio para mujeres era firmado con pseudónimo. Salus era el de Balagué y sus colaboradoras eran Georgette, Pompadour y Maintenon. ¿Qué significó ese primer programa de radio femenino? La respuesta a esta pregunta de arranque se descubrirá en estas paginas.

\section{Metodología}

El objetivo de este artículo es evidenciar cuál fue la contribución de los programas femeninos de Radio Barcelona y de sus realizadoras a la historia de la radio de los años 20 en Cataluña.

Las aportaciones de este escrito son fruto de una revisión de las revistas de contenido radiofónico editadas en Cataluña entre 1920 y 1930, focalizando especialmente la búsqueda en los años 20, momento de creación de los programas destinados a un target femenino. Del marco temporal descrito se conservan más de 40 cabeceras en los archivos de la Casa de l'Ardiaca y de Radio Barcelona. Son publicaciones de índole muy diferente que se fijaban en aspectos tan dispares como la técnica o el humor en la radio. A partir de esta literatura y del seguimiento en prensa de la programación de Radio Barcelona, especialmente en La Vanguardia, se ha rastreado la pista de los programas para mujeres desde su aparición en la pionera EAJ-1. El manejo de estas ediciones ha permitido ligar a una desconocida María Cinta Balagué con los relatos pioneros de la radio puesto que los escritos hasta ahora no la mencionaban. Saber quien era y por qué su nombre se vincula a la Telefonía Sin Hilos de la primera estación española se convierte en otro objetivo del trabajo desarrollado.

Esta exploración debe enmarcarse en la investigación exhaustiva y cualitativa que se llevó a término para mi tesis doctoral, Les locutores de ràdio a Catalunya, 19241939, leída en la Universidad Autónoma de Barcelona en 2008. El eje metodológico 
principal fueron las historias de vida y las entrevistas-cuestionario trianguladas a partir de la literatura sobre historia de la radio editada desde la Academia y desde la profesión. En esta línea y para la ejecución de este artículo se han tenido en cuenta Guillamet (1994), Balsebre (2001), Franquet (2001), Faus (2007), Martí (1990) o Fernández Sande (2006) así como las aportaciones firmadas por profesionales del sector, como: Salillas y Rafel (1980) o Munsó Cabús (2006) . El análisis de la programación de la radio de los años 20 sólo se puede hacer a través de las referencias impresas puesto que en los años 20, la radio se hacía en directo.

\section{Las emisiones para mujeres en la radio catalana de los años 20}

Las primeras emisiones femeninas de los años 20 del siglo pasado en España tenían dos características específicas: eran escasas y podían ensayar formas nuevas de comunicación. Los programas para mujeres eran de poca duración, exactamente igual que el resto de la programación de las emisoras y significaron una puerta abierta hacia un nuevo campo laboral que algunas mujeres supieron aprovechar para entrar a trabajar o a colaborar en la radio. Por poner sólo algunos ejemplos que contextualizan y definen el tipo de programación para mujeres basta ver que en tres estaciones pioneras, Radio Barcelona, Radio Catalana (Cataluña) y Radio Ibérica (Madrid), las mujeres tuvieron roles muy diferentes. En Radio Barcelona se les permitió jugar con las posibilidades de expresión del nuevo medio. En Radio Catalana, su papel en los albores del media, casi todo estaba por escribir, fue más insignificante, a pesar de que los responsables de la estación se vanagloriaban de una programación más creativa que la de su rival. Y así fue, por ejemplo, cuando en Radio Catalana se crearon ambientes sonoros para contextualizar novelas radiadas, una gran novedad que se inscribiría en la línea defendida por el autor de la Estética Radiofónica.

Los programas radiofónicos pueden servir de decorado sonoro a las actividades de la vida cotidiana. (...) La radio no sólo ofrece al radioyente la posibilidad de concentrarse en palabras y en la música sino que le permite dejar vagar sus pensamientos todo lo lejos que desee. (...) La radio no sólo no está supeditada a referencias de tipo geográfico sino que también le está permitido utilizar formas sonoras para plasmar ideas, sueños, criaturas fantásticas, dioses o personificación de cosas. ${ }^{2}$

Mientras que en Barcelona, las oyentes debían conformarse con las Charlas Femeninas de Joaquín Arrarás que Radio Barcelona emitía desde noviembre de 1924 o con las cortísimas intervenciones de la desconocida y única mujer anunciadora de Radio Catalana; en Madrid, Radio Ibérica que empezó sus emisiones antes que Radio Barcelona (Fernández Sande, 2006:77) emitía conferencias marcadamente feministas como recogen Gil Gascón y Gómez García (2010: 133). La periodista Teresa Escoriaza se dirigía a su audiencia descubriendo a las mujeres las posibilidades de la radio para acceder a una cultura que les era vetada. 
Aunque los prejuicios milenarios continúen privándonos de recibir una educación amplia y sólida, por impedirnos asistir a los centros culturales; aunque las costumbres absurdas sigan apartándonos de la vida activa, confinándonos al hogar, convertido así en cárcel; aunque las leyes injustas nos obliguen a ocupar un lugar secundario en el mundo consciente, las ondas redentoras, portadoras del alimento espiritual, llegarán de hoy en adelante hasta nosotras. ${ }^{3}$

De signo muy diferente era el tono usado por Arrarás. Los monólogos para mujeres de este corresponsal de El Debate en Barcelona, dejan de emitirse cuando este periodista decide dedicarse de pleno al periodismo impreso y se aparta de la radio a finales de la década. Arrarás fue corresponsal de guerra de la Oficina de Prensa y Propaganda de Franco, durante la Guerra Civil.

Su vacío en radio Barcelona lo ocuparían un elenco de chicas que crearon, sin ser muy conscientes de ello, el primer magazine radiofónico en la acepción de Martí (1999: 27). La verdadera revolución en la programación femenina se produjo casi por casualidad y mientras en Radio Barcelona, las mujeres ganaban espacio en la locución, en la otra estación de la capital, Radio Catalana, la presencia femenina en antena era muy poco destacable.

Radio Catalana, la hermana y competidora desde 1925 de Radio Barcelona, nació del empresario Hugo Heusch y se asoció a Radio Ibérica. Esta emisora que arrancó con un marcado carácter industrial, se convirtió en un medio de entretenimiento con un objetivo muy claro: ofrecer una programación sin los estorbos de la publicidad para potenciar sus emisiones de forma limpia. Apostó por los contenidos y aunque supo marcar la diferencia con su rival en este extremo, no lo evidenció en el capitulo de personal femenino que siempre tuvo un papel poco preponderante. Su centro emisor arrastraba sus ondas a bastantes quilómetros de Barcelona con lo que se adjudicaba una cobertura muy amplia del territorio catalán (Guillamet, 1994:110). Con estas cartas de presentación, los gestores de la emisora pretendían que sus asociados contribuyeran con holgura para su manutención.

una pequeña colaboración de los señores aficionados a la radiotelefonía(...) quienes mediante una pequeña cuota mensual podrán proporcionarnos un ingreso que sustituya al que habría de reportarnos el anuncio. ${ }^{4}$

La colaboración económica fue insuficiente y en 1929 Radio Catalana apaga su voz para fusionarse con Radio Barcelona, y integrarse así también a la importante red que Ricardo Urgoiti, de Unión Radio, estaba tejiendo por todo el país.

3.1. ¿Por qué se contratan locutoras?

En Cataluña, los primeros espacios para mujeres con continuidad son los que Radio Barcelona puso en antena a partir de 1924, primero con Arrarás y sus conferencias, más tarde, 1926, los que protagonizan chicas locutoras. Radio Catalana sólo tuvo programación diaria de 19:00h. a 00:00h. y de 1925 a 1929. Dentro de su franja programática introducía radio novelas, cursos de idiomas como Berlitz Corner, patrocinado por la academia del mismo nombre, programas para caballeros, 
retransmisiones de fútbol y espacios para mujeres con consejos sobre moda o apuntes de la vida social de Barcelona. Este espacio que no tuvo un nombre concreto era leído por el locutor estrella de la casa, Alberto Buchelli. La única mujer que trabajó en esta estación, de biografía imposible de rastrear, fue una anunciadora. Se encargó solamente de leer publicidad y no intervino jamás (Salillas y Rafel, 1980: 42) en las tareas propias de una locutora es decir, en presentar la programación hilvanándola con estilo suficiente para crear un continuo sonoro.

Los primeros programas femeninos de Cataluña, con estructura estable, hay que atribuirlos a una perfecta desconocida para la historia escrita de la radio. La creadora del formato de radio que luego más se utilizaría en el medio fue una colaboradora de Radio Barcelona, Maria Cinta Balagué que trabajaba en el Ayuntamiento de la ciudad condal.

En 1926, el director de la revista que editaba la estación, Salvador Raurich escribe un artículo preguntándose como sonaría Radio Barcelona si incorporase voces femeninas a su antena. Respondiéndose a su retórico planteamiento, Raurich que era además el crítico musical de la emisora se muestra convencido de que se embellecerían las emisiones de la estación decana catalana.

Una bien timbrada voz femenina parece sonar mucho más grata, más acústicamente fiel al oído, por vía éter, que las graves y adustas sonoridades del órgano vocal masculino. Quizás podríamos encontrar la razón acústica de este fenómeno aparente buscando similitudes o afinidades en el campo de los instrumentos musicales(...) parece como si las audiciones de EAJ-1 resultan más transparentes, más poéticas, más luminosas, más floridas...[se refiere al momento en que las mujeres han llegado a la locución $]^{5}$

Esta es una explicación que justifica la llegada de mujeres a la programación femenina. Otro motivo, visto anteriormente, es la dedicación del "padre" de Charlas Femeninas a otros quehaceres dejando un espacio para ocupar. Hay más causas que razonan el porqué de la contratación de mujeres en la radio. No existe un solo motivo que explique ese comportamiento laboral. Se trata de un proceso natural y de la coincidencia de varias circunstancias en un mismo momento. Por ejemplo, las estaciones de radio que operaban en Europa o en los EEUU, durante aquellos mismos años 20, ya tenían locutoras trabajando y si en Cataluña se copiaron los programas e incluso los modelos técnicos y de emisión de esos países extranjeros, es obvio pensar que poner locutoras era otra de las características que había que importar.

Una razón más hay que atribuirla al target y a la publicidad. Durante la década de los años 20, la radio se escuchaba principalmente en casa (había muy pocos hogares con aparatos receptores, eran caros y había que pagar un canon por tenerlo) y en algunos lugares públicos como los casinos o los clubes de radioyentes. En los horarios de emisión, mediodías y/o noches (coincidían con las comidas), eran las mujeres las que principalmente estaban en casa (señoras y criadas) por lo que esa primera radio tenía una importante audiencia femenina que interesaba contentar. Fidelizar a las mujeres como oyentes significaba además de tener un público estable, abrir una 
línea comercial fácilmente explotable y la radio en este país, como es sabido, nace de manos privadas y desde muy pronto se revela como un negocio un tanto ruinoso (Faus, 2007: 193 ). Las oyentes que tenían aparato receptor en casa, tenían poder adquisitivo y eran también mujeres cultivadas que leían revistas femeninas plagadas de anuncios. Este móvil económico ayuda mucho a la incorporación de locutoras a la radio. ¿Quién mejor que una mujer para hablarle sobre temas o productos femeninos a otra mujer? Los propietarios de las emisoras pronto se dan cuenta del filón que han descubierto y se dan prisa para hacer con sus programas de radio, una versión hablada de lo que sus oyentes ya estaban acostumbradas a leer: consejos de belleza, modas, relatos de sociedad, críticas de música o teatro y literatura.

\subsection{Los primeros programas femeninos en Cataluña}

Balsebre (2001) consideraba el programa de Radio Barcelona Radioémina, dirigido por Mercedes Fortuny en 1930 como el primer magazine radiofónico pero entonces todavía no se conocían las aportaciones de las locutoras a la historia de la radio con lo que se evidencia la necesidad de rescribir algunos de los pasajes más antiguos del media. Sin duda Radiofémina fue un programa singular para las oyentes de radio catalanas. De hecho Radio Barcelona contrató a la gran actriz Carmen Martínez-Illescas Naveiras para ponerle voz al espacio que fue querido y seguido, a la par, y que después de la Guerra Civil se mantuvo en antena, con todos los ajustes que requería el nuevo marco social español, y con distintas voces, pero no fue el primero. Munsó Cabús (2006: 23) atribuye los aorígenes incluso a Ràdio Associació de Catalunya, mucho más tardía en aparición.

Sin embargo con anterioridad, en tiempos de Ràdio Associació de Catalunya, los mismos laboratorios que impulsaron su emisión -los artífices del celebre 'Eupartol' -ya habían patrocinado un espacio de características similares, 'Diari Femení', emitido entre las doce y la una del mediodía, según consta en el número 15 de 31 de marzo de 1936 de Radio Publicitat, boletín editado mensualmente por la sección comercial de la emisora. ${ }^{6}$

Pero lo cierto es que, algunos años antes de Radiofémina y a raíz de las razones esgrimidas anteriormente, Radio Barcelona ya tuvo un espacio femenino hablado por mujeres. Para ello se puso en contacto con el Instituto de Cultura y Biblioteca popular de la Mujer, prestigiosa institución en la que se daban clases de cultura general a jóvenes, y al mismo tiempo se las formaba en los quehaceres del hogar. Para la fundadora, Francesca Bonnemaison, la finalidad del Instituto era la transformación de la mujer en un ser independiente y fuerte "capacitada para ocupar dignamente el lugar que la naturaleza femenina tenia destinado: el hogar y la educación y formación de la familia de aquellos que deben erigirse como las nuevas generaciones"(Nash et al. 1975:25) El Instituto propone a su vez, a sus asociadas, el reto de Radio Barcelona y el llamamiento es respondido por Maria Cinta Balagué que será capaz de vestir un programa de radio impregnado de la filosofía del Institut y sin experiencia previa. 
Así pues, se estrena en 1926 una Sección Literaria Femenina, dentro de la programación que Radio Barcelona dedicaba a las mujeres que llevaba como nombre genérico Radio telefonía femenina (usando tres palabras) según La Vanguardia de los años 1926 y 1927 que identificaba así a esos 20 o 30 minutos de antena, según el dia. Esta programación femenina ocupaba las tardes, a partir de las 18.00h. La Sección Literaria Femenina fue un programa para difundir las creaciones de las oyentes con inquietudes literarias. Era bisemanal, martes y viernes y la propia presentadora, con pesudónimo, Salus era la encargada de dar voz a estos escritos. Ese mismo año, el estrato de la programación dedicado a las féminas pasará a contener:"Sección de modas" y "Sección de temas útiles". Era el mismo espacio, en el mismo horario pero que se llenó de más contenido y a su vez amplió el abanico de temas dando cabida a un grupo de colaboradoras fijas. Las colaboradoras de Balagué en este programa eran especialistas en los "temas femeninos" del momento: "modas y temas útiles". Todas eran mujeres de un alto nivel cultural y económico que además escribían sobre los mismos conceptos de los que hablaban por la radio ("modas, temas útiles y ciencia doméstica") en revistas femeninas de los mismos años. Así pues, la Señorita Pompadour se encargaba de la sección "Modas"y la Señorita Maintenon de la sección "Ciencia domestica" y Balagué continuaba poniendo en antena las composiciones de las oyentes y de éstas escritoras que eran sus guionistas, según se deduce de la descripción de la programación referida en La Vanguardia, aunque la propia Balagué escribió sobre la necesidad de que más colaboradoras como las suyas dejaran oír su voz (Nota 9).

La Sección de modas y la de Temas útiles era un programa cerrado, siempre ocupó el mismo día y la misma hora, minutos más o menos según el año, tal como publicó la prensa. En 1927 la Vanguardia, se refería a esos 20 minutos para chicas, como Radiotelefonía femenina (usando ahora sólo dos palabras) un nombre genérico que sustituye a los también genéricos Sección Femenina o Sesiones femeniles. Todos sirvieron como identificadores universales de las emisiones específicas para señoras, cosa que ha contribuido a complicar la identificación concreta de los programas, especialmente cuando el nombre se publico indiferentemente en vocablos juntos o separados. Sea como fuere, durante los años 1926,1927, 1928 y hasta febrero de 1929, las emisiones de tarde para mujeres de Radio Barcelona radiaban contenidos específicos de su agrado y Maria Cinta Balagué fue la locutora que les puso voz. Como se puede observar fue un espacio corto en antena pero de larga duración en la programación habitual de la EAJ-1, consolidándose en una franja invariable de la programación. Por todo ello es posible calificarlo como de primer Magazine radiofónico, un programa con entidad propia y diferenciada (Martí, 1990:27) que la prensa singularizaba a partir de la locutora.

Es una distinguida señorita que ejerce de locutora en las sesiones femeniles que, con los titulo MODAS Y TEMAS UTILES, los martes y los viernes suele radiar EAJ-1, y que llevan las firmas de Georgette y Pompadour, del Instituto de cultura y biblioteca Popular de la Mujer. 
Esas pioneras de la programación moderna incorporan en su espacio una novedad de indiscutible interés para los estudios de la comunicación: los oyentes tienen opción de poderse convertir en emisores en un proceso de comunicación. Balagué y sus compañeras facilitan a las oyentes que lo deseaban "previa prueba de voz" la puesta en antena sus propios escritos o poemas, ya desde el inicio del espacio, lo que queda recogido en la revista Radio Barcelona, número 121 de 1926. Además, las oyentes pueden mandar cartas con peticiones que son recogidas y respondidas en el programa, o solicitar discos, cosa que contribuye a la popularización del espacio y claro está, de la radio como medio de comunicación.

En febrero de 1929, Balagué y sus colaboradoras desaparecen de la programación de la EAJ-1 que vuelve a la carga con otras charlas para mujeres. Esta vez, Charlas Femeninas (igual nombre que el programa pionero de Arrarás) que si bien empiezan ocupando el lugar de Balagué, martes y viernes a partir de las 18.00h, muy pronto se programa a las $17 \mathrm{~h}$. y modifica el nombre dejándolo en Charlas para la Mujer Este espacio, también de corta duración, está interpretado por el Duendecillo de las Ramblas, pseudónimo del locutor que dió voz a los guiones de la escritora María del Patrocinio Alba. Con este programa Radio Barcelona cruzará la frontera temporal para sentarse en los años 30 .

\subsubsection{La primera locutora de Radio Barcelona}

Balagué, esa distinguida señorita a la que se referían las publicaciones anteriores, sí fue la primera locutora de radio de la historia. Sabaté no. María Sabaté trabajó cinco años en Radio Barcelona a las órdenes de Joaquín Sánchez Cordobés, director de la EAJ-1 en los años 20. Él mismo firmó, a petición de la interesada, su baja voluntaria evidenciando cuál había sido su ocupación real en la estación.

Maria Sabaté Cebado ha prestado sus servicios en estas oficinas durante 5 años como mecanógrafa-secretaria de la Dirección, conociendo taquigrafía y los idiomas francés e inglés, habiendo cumplido fielmente su cometido, dejando de prestarnos sus servicios como tal, voluntariamente. ${ }^{8}$

María Sabaté fue colocada en Radio Barcelona por la Asociación Nacional de Radiodifusión (ANR). Esta agrupación de radiofonistas y empresarios, socios en distintas catagorías de la radio (Franquet; 2001:43) financió la compra y la instalación de la primera emisora de EAJ-1 y soportó su déficit económico. La agrupación había contratado a Sabaté como secretaría antes de que la radio empezara sus emisiones. Su cometido consistía en redactar las actas de las reuniones de socios. Su llegada a la radio coincide con la puesta en marcha de la emisora por lo que esta primera funcionaria pudo muy bien colaborar en las pruebas técnicas iniciales, prestándose a leer, para que el ingeniero de la estación pudiese calibrar la voz de forma adecuada. De hecho, su carácter jovial y extravertido y sus 22 años son activos que se suman a esta teoría, tesis que queda absolutamente fundamentada cuando la propia Sabaté ya mayor, entrevistada en El Correo Catalán en 1974 afirma no acordarse de ninguno de sus programas. En Radio Barcelona, en los años 20 los locutores son, y por este 
orden, Rafael del Caño y después de su marcha, Josep Torres Vilalta, Toresky y José Miret.

Así pues, María Cinta Balagué en los años 20 se convierte en la primera mujer locutora de un espacio de Radio en Cataluña. Como locutora daba paso a los contenidos de su espacio, que tuvo bastantes seguidoras a tenor de la relación epistolar que mantuvo con sus oyentes, otra novedad en la época. Gracias a una carta-respuesta a su publico, se puede deducir que Balagué era una mujer cultivada, en este fragmento puede observarse su dominio del lenguaje, y que además de conservadora no tenía escrúpulos cuando de aleccionar al público se trataba.

(...)lamentándonos al mismo tiempo, que no haya más Georgettes que, lanzando su voz al espacio, templen un poco la atmósfera que respiran estas muchachitas que dándoselas de intelectual, van leyendo en los tranvías novelas cinematográficas y cosas de muy mal gusto, sin otra preocupación que de levantar de vez en cuando sus ojos para ver si algún efebo les dirige sus miradas; u aquellas otras de las modernas mujeres -que creen serlo, pero que no lo son en el elevado concepto de La palabrapara volviendo su vista hacia atrás, vuelvan también a sus hogares, ávidos de su presencia y su guía y se consagren a la familia como es su deber, y la encaminen y la lleven por el sendero de la virtud que es el que conduce a la felicidad humana y al bienestar de los pueblos. ${ }^{9}$

María Cinta Balagué nació en Barcelona en 1989 y con sus estudios finalizados ingresó en el Ayuntamiento de la capital dónde ejercía de secretaria del alcalde José María de Porcioles. Fue la primera mujer funcionario de un ayuntamiento en el que se jubiló. Su dedicación al servicio público le valió la obtención de la Medalla de Plata del Mérito al Trabajo (1976) y de la Medalla de la Ciudad en reconocimiento de sus méritos en la gestión municipal (1971). Murió en Barcelona en 1985, siendo soltera.

\section{Conclusiones}

La historia de la radio catalana se tiene que reescribir para incluir el preponderante papel que tuvieron las locutoras en la construcción y desarrollo del media. Las aportaciones de los programas femeninos en los albores de Radio Barcelona son tan interesantes como poco conocidas. El hecho de que el primer programa con estructura (Magazine) fuese encargado a mujeres con una alta formación indica que la radio se tomaba muy en serio su faceta pedagógica, pero también puede enviarnos indicios sobre cuán importante era el target femenino para afianzar y fidelizar a una audiencia que tenía que crecer al mismo tiempo que el media. La solicitación de discos por parte de las oyentes o la puesta en antena de sus propias creaciones literarias sitúan a este público en una nueva dimensión que no se puede desperdiciar. Los primeros oyentes de radio no eran sujetos pasivos. Eran actores activos que interactuaban con sus emisores y que además opinaban sobre la programación, enviando cartas a las estaciones que con frecuencia eran respondidas en las revista-boletín de la radio. Los discos que demandaban las oyentes de Balagué bien pueden ser el origen del mítico 
programa Discos Dedicados que hizo las delicias de tantos españoles después de la Guerra Civil.

Así pues, la exploración llevada a término evidencia, una vez más, como la historia coloca en el imaginario colectivo verdades absolutas que no siempre se acercan a los hechos acontecidos (María Sabaté) y se olvida de protagonistas que tuvieron un papel relevante por reivindicar. Este fue el caso de María Cinta Balagué, la primera locutora de Radio Barcelona.

\section{Bibliografía}

ARIAS CARDONA, J. (1933). Guía de las emisoras de radio de toda España. Obra curiosa y de utilidad. Barcelona.

ARNHEIM, R.(1980). Estética radiofónica. Barcelona: Gustavo Gili, S.A.

BALSEBRE, A. (2001). Historia de la Radio En España. 2 volúmenes. Madrid: Cátedra.

ESPINOSA, S. (2008) Les locutores de ràdio a Catalunya, 1924-1939. UAB: Tesis Doctoral http://www.tdx.cat/TDX-0331109-152709 [9-10-2013]

FAUS, A. (2007). La radio en España (1896-1977). Madrid: Taurus

FERNÁNDEZ SANDE, M. A. (2006) Los Orígenes de la radio en España. Madrid: Fragua.

FRANQUET, R. (2001). Historia de la ràdio a Catalunya al segle XX: de la ràdio de galena a la ràdio digital. Barcelona: Generalitat de Catalunya.

GIL GASCÓN, F. Y GOMMZ GARCÍA, S. (2010). "Al oído de las mujeres españolas. Las emisiones femeninas de Radio Nacional de España durante el primer franquismo (1937-1959)" En: Estudios sobre el mensaje periodístico, no 16, Madrid: UCM. p.131-143

GUILLAMET, J. (1994). Història de la premsa, la ràdio i la televisió a Catalunya 1641-1994 Barcelona: La Campana

MARTI, JM. et al.(1990). Modelos de programación Radiofónica. Barcelona: FeedBack.

MUNSÓ CABÚS, J. (2006). Tiempo de radio (1978-1990): Memorias de cadena catalana. Barcelona: L'esfera dels llibres.

NASH, M. et al. (1975) .Mujeres libres: España 1936-1939 Barcelona: Tusquets.

PÉREZ PUJOL, R. (dir.) (1936). Anuario de la radio. Barcelona: Barcelona.

SALILLAS, JM. y RAFEL LLENA, A. (1980). 50 años de EAJ 15. Radio associació de Catalunya, Radio España de Barcelona. Barcelona: Picazo.

Radio Barcelona, 1924, 1925, 1928, 1929. (Todos los números de esas fechas)

Ràdio Catalana, 1925, 1929. (Todos los números de esas fechas)

La Vanguardia, 1926, 1927, 1928, 1929, 1930. (Todos los números de esas fechas)

La Veu de Catalunya, 1924. (Todos los números de esa fecha) 


\section{NOTAS}

1 Para ampliar los detalles sobre el mito radiofónico de María Sabaté, ver ESPINOSA, S. (2008) Les locutores de ràdio a Catalunya, 1924-1939. UAB: Tesis Doctoral http://www.tdx.cat/TDX-0331109152709 [9-10-2013], p. 204-211.

2 Arnheim, R. (1980: 13) se refería a la revolución estética de los mensajes que la radio a través de su propio lenguaje podía difundir, extremo éste que en las emisiones de Ràdio Catalana se explotaron debidamente.

3 GIL GASCÓN, F. Y GÓMEZ GARCÍA, S. (2010). “Al oído de las mujeres españolas. Las emisiones femeninas de Radio Nacional de España durante el primer franquismo (1937-1959)" En: Estudios sobre el mensaje periodístico, $\mathrm{n}^{\circ}$ 16, Madrid: UCM. p.131-143

4 SALILlAS, JM. y RAFEL LLENA, A. (1980). 50 años de EAJ 15. Radio associació de Catalunya, Radio España de Barcelona. Barcelona: Picazo.

5 Revista RADIO BARCELONA, Número 121, 1926.

6 MUNSÓ CABÚS, J. (2006). Tiempo de radio (1978-1990): Memorias de cadena catalana. Barcelona: L'esfera dels llibres.

7 Revista RADIO BARCELONA, Número 233, 1929.

8 Archivo personal de la familia Sabaté Cebado.

9 Revista RÀDIO BARCELONA. Número 233, 1929:11.

\section{La autora}

Sílvia Espinosa-Mirabet, Doctora en Comunicación Audiovisual y Publicidad por la Universidad Autònoma de Barcelona (UAB) trabaja en la Universidad de Girona (UdG) dónde imparte docencia en el Grado de Publicidad y Relaciones Públicas y en el Màster de Comunicación Cultural. Su interés por las metodologías activas (investigación) se traduce en asignaturas con un marcado acento creativo. Ha trabajado en 3 de las universidades públicas de Cataluña y goza de experiencia profesional en la radio (Cadena SER). Sus investigaciones más recientes se centran en el análisis de los operadores del sector radiofónico: locales, nacionales o internacionales; la historia de los mass media desde una perspectiva de género o las hibridaciones audiovisuales. Dirige la Xarxa d'Innovació Docent 1 de la UdG, dónde es considerada Investigadora en Activo y forma parte del grupo estable de investigadores del Observatori de la Radio de Catalunya y de ARPA (UdG). 